\title{
SENSIBILIDADE DA SALMONELLA ABORTIVOEQUINA A QUIMIOTERAPICOS E ANTIBIÓTICOS
}

CURY, R. - Sensibilidade da Salmonella abortivoequina a quimioterápicos e antibióticos. Kev. Fac. Med. vet. Zootec. Univ. S. Paulo, 11:111-14, 1974 .

Resumo: Antibiogramas realizados com oito amostras de Salmonella abortivoequina de diferentes procedências, frente a dezenove antibióticos, um antı́ungico e trôs quimioterápicos demonstraram que foram elas sensiveis ao cloranfenicol, kanamicina, metaciclina, cefaloridina, cefalotina e penetracina.

UnITERmos: Sensibilidade *; Salmonella abortivoequina *; Quimioterápicos*; Antibioticos*.

\section{INTRODUCAO E IITTERATURA}

Encontramos na literatura várias indicaçỏes sobre o uso de alguns antibióticos e de certos quimioterápicos no tratamento de infecçōes devidas à Salmonella abortivoequina. Todavia, são poucas as referências sobre a sensibilidade da salmonella supra-citada à ação dessas drogas.

BRYANS et al. ${ }^{3}$, em 1961, baseados em antibiograma feito pelo método dos discos, selecionaram três compostos: nitrofurazona, sulfato de neomicina e nitrofurantoina. A administração desses medicamentos a potros infectados mostrou que eles continuaram a eliminar a Salmonella abortivoequina durante e após o tratamento.

Aliás, tratamento com resposta negativa já tinha sido observado por WILLEMS \& STIERNET 8, em 1945. Usando prepara- dos sulfamídicos e penicilina não conseguiram evitar 0 aborto em águas infectadas.

GARBERS \& MONTEVERDE 5, em 1964, fizeram antibiogramas com a Salmonella abortivoequina e verificaram que nảo houve halo de inibição com: penicilina, terramicina, aureomicina, bacitracina, eritromicina, tetraciclina, novobiocina, elkosin, gantrisin, sulfadiazina, sulfamerazina $€$ sulfametazina; produziram-se halos nitidos (2 $\mathrm{mm}$ - segundos os autores), sem aparecimento de mutantes, com a polimixina $\mathrm{B}$. Os maiores halos (5 a $8 \mathrm{~mm}$ ) foram obtidos com cloromicetina e dihidroestreptomicina, embora com ambas se tenha notado a presença de mutantes. Os nitrofuranos comportaram-se de modo semelhante à polimixina $B$, porém, com zonas de inibiçāo de aproximadamente o dobro do tamanho.

- Professor Assistente Doutor do Departamento de Medicina Veterinária Preventiva e Saúde Animal, da Faculdade de Medicina Veterinária e Zootecnia da USP. 
CURY, R. - Sensibllidade da Salmonella abortivoequina a quimioterápicos e antibióticos. Rev. Fac. Men. vet. Zootec. Univ. S. Paulo, 11:111-14, 1974.

Dispondo de várias amostras de Salmonella abortivoequina de diferentes procedências, resolvemos ensaiar sua sensibilidade frente a vários antibióticos e a alguns quimioterápicos.

\section{MATERIAL E METODOS}

2.1. Germes: usamos as seguintes amostras de Salmonella abortivoequina:

624 (original: Instituto R. Roch, Berlin) 705 (original: NCTC, Washington)

270 (original: Statens Seruminst., Copenhagen)

6.900 I (Instituto Biológico de Sāo Paulo) 6.900 II (Instituto Biológico de São Paulo)

7.571 (Instituto Biológico de São Paulo

SPV 15 - Santa Rita, Estado de S. Paulo

SPV 22 - Pindamonhangaba, Estado de São Paulo.

As amostras SPV 15 e SPV 22 foram isoladas e identificadas por nós. Todas as amostras usadas nesse trabalho eram mantidas em ágar chocolate e ressemeadas cada três semanas.

2.1.1. Camundongos: foram utilizados camundongos albinos, de tamanho médio (cerca de $13 \mathrm{~g}$ ), recebidos da criação do Instituto Biológico de São Paulo.

2.2. Antibiograma: utilizaram-se discos de papel filtro de $6 \mathrm{~mm}$ de diâmetro ${ }^{1}$. A concentração das substâncias obedeceu às sugestões da "Federal Food and Drug Administration" conforme as indicaçôes de BIERINGER \& MIALE 2, em 1961.

2.2.1. Meio de Cultura: fol usado o DST ágar CM 261, Oxoid com $7 \%$ de sangue desfibrinado de carneiro. Esse meio preenche os critérios da OMS T.

2.3. Técnica de execução: antes de serem usadas nos antibiogramas as amos- tras de salmonelas foram reativadas, procurando-se selecionar formas lisas (S) virulentas.

Efetuaram-se, em seqüência:

a) várias passagens em ágar amido solúvel de CROSSLEY et al. ${ }^{4}$, em placas de Petri, meio este que, segundo os autores, impede o desenvolvimento de formas rugosas ( $R$ ), permitindo apenas o crescimento de colônias lisas (S);

b) inoculações das amostras em camundongos e reisolamento, procurando-se assim reativar a virulência.

Os antibiogramas foram efetuados partindo-se de culturas resultantes da semeadura das amostras em caldo simples, incubadas a $37^{\circ} \mathrm{C}$ durante 24 horas.

$O$ inóculo foi constituído de $0,1 \mathrm{ml}$ de cada cultura espalhado em separado, em placa de Petri, sobre o DST ágar com sangue. As placas semeadas permaneceram uma hora em ambiente. Colocaram-se então os discos ${ }^{6}$.

As placas foram invertidas, levadas à estufa a $37^{\circ} \mathrm{C}$ e mantidas aí durante 24 horas, findas as quais foi feita a leitura.

Foram executadas duas repetiçôes dos antibiogramas.

3. R E S L T A D O S

Figuram na Tabela 1.

Verificou-se, nesses antibiogramas, que a Salmonella abortivoequina representada pelas oito amostras utilizadas, foi muito sensivel a: cloranfenicol, kanamicina, metaciclina, cefaloridina, cefalotina e penetracina.

Interessante anotar grande sensibilidade a uma combinação de estrutura complexa de penicilina e tetraciclina (Penetracina), ao lado do fato das amostras serem resistentes à penicilina e apresentar sensibilidade varíavel à tetraciclina, quando esses antibióticos foram provados em separado. 
CURY, R. - Sensibilidade da Salmonella abortivoequina a quimioteráplcos e antibióticos. Rev. Fac. Med. vet. Zootec. Univ. S. Paulo, 11:111-14, 1974.

T A B E L A 1

Resultados dos antiblogramas de oito amostras de Salmonella abortivoequina.

A leitura fol efetuada de acordo com o diametro do halo de inibicăo.

\begin{tabular}{|c|c|c|c|c|c|c|c|c|c|}
\hline \multirow[b]{2}{*}{ Agente } & \multirow[b]{2}{*}{$\begin{array}{l}\text { Disco } \\
\text { de: }\end{array}$} & \multicolumn{8}{|c|}{$\begin{array}{c}\text { Salmonella abortivoequina } \\
\text { Amostra n.o: }\end{array}$} \\
\hline & & ఫ్ర & 몽 & $\stackrel{ }{*}$ & $\begin{array}{l}\text { ' } \\
\stackrel{\circ}{\circ} \\
\dot{0}\end{array}$ & $\begin{array}{l}\text { घ } \\
\text { \&े } \\
\text { oे } \\
0\end{array}$ & 官 & $\begin{array}{l}28 \\
\overrightarrow{2} \\
\overrightarrow{2}\end{array}$ & $\begin{array}{l}\text { สี } \\
\text { ฉั } \\
\text { ฟั }\end{array}$ \\
\hline Penlcilina & 10 UI & $\mathbf{R}$ & $\mathbf{R}$ & $\mathbf{R}$ & $\mathbf{R}$ & $\mathbf{R}$ & $\mathbf{R}$ & $\mathrm{R}$ & $\mathbf{R}$ \\
\hline Dinidroestreptomicina & $10 \mathrm{meg}$ & $\mathbf{R}$ & $\mathbf{R}$ & $\mathbf{R}$ & ++ & ++ & $\mathbf{R}$ & +++ & $\mathbf{R}$ \\
\hline Eritromicina & $15 \mathrm{mcg}$ & $\mathbf{R}$ & $\mathbf{R}$ & $\mathrm{R}$ & $\mathbf{R}$ & $\mathbf{R}$ & $\mathbf{R}$ & $\mathbf{R}$ & $\mathbf{R}$ \\
\hline Cloranfenicol & $30 \mathrm{mcg}$ & +++ & +++ & +++ & +++ & +++ & +++ & +++ & +++ \\
\hline Novoblocina & 30 $\mathrm{mcg}$ & $\mathbf{R}$ & + & $\mathbf{R}$ & $\mathbf{R}$ & $\mathbf{R}$ & $\mathbf{R}$ & $\mathbf{R}$ & $\mathbf{R}$ \\
\hline Kanamlcina & $30 \mathrm{mcg}$ & +++ & +++ & +++ & +++ & +++ & +++ & +++ & +++ \\
\hline Neomicina & $30 \mathrm{mcg}$ & $\mathbf{R}$ & ++ & + & + & ++ & + & $\mathbf{R}$ & $\mathbf{R}$ \\
\hline Espiramicina & $30 \mathrm{mcg}$ & $\mathbf{R}$ & $\mathbf{R}$ & $\mathbf{R}$ & $\mathbf{R}$ & $\mathbf{R}$ & $\mathbf{R}$ & $\mathbf{R}$ & $\mathrm{R}$ \\
\hline Colimicina & $16.000 U$ & ++ & + & + & + & + & ++ & + & + \\
\hline Oxitetraciclina & $30 \mathrm{mcg}$ & ++ & +++ & ++ & ++ & ++ & + & ++ & ++ \\
\hline Tetraciclina (*) & $30 \mathrm{mcg}$ & + & + & +++ & + & + & ++ & ++ & ++ \\
\hline Rifamiclna & $30 \mathrm{mcg}$ & $\mathbf{R}$ & + & $\mathbf{R}$ & $\mathbf{R}$ & $\mathbf{R}$ & $\mathbf{R}$ & $\mathbf{R}$ & $\mathbf{R}$ \\
\hline Ambramicina (*) & $30 \mathrm{mcg}$ & + & ++ & + & + & + & ++ & ++ & ++ \\
\hline Metaciclina & $30 \mathrm{mcg}$ & +++ & +++ & +++ & $+t+$ & +++ & +++ & +++ & +++ \\
\hline Pristinamiclna & $30 \mathrm{mcg}$ & + & + & + & + & + & ++ & + & + \\
\hline Leucomicina & $30 \mathrm{mcg}$ & $\mathbf{R}$ & $\mathbf{R}$ & $\mathbf{R}$ & $\mathbf{R}$ & $\mathbf{R}$ & $\mathbf{R}$ & $\mathbf{R}$ & $\mathbf{R}$ \\
\hline Cefaloridina & $25 \mathrm{mcg}$ & +++ & +++ & +++ & +++ & +++ & +++ & +++ & +++ \\
\hline Cefalotina & $25 \mathrm{mcg}$ & +++ & +++ & +++ & +++ & +++ & +++ & +++ & +++ \\
\hline Penetracina (**) & $10,5 \mathrm{mcg}$ & +++ & +++ & +++ & +++ & +++ & +++ & +++ & +++ \\
\hline Nistatina & $60 \mathrm{mcg}$ & $\mathbf{R}$ & $\mathbf{R}$ & $\mathbf{R}$ & $\mathbf{R}$ & $\mathbf{R}$ & $\mathbf{R}$ & $\mathbf{R}$ & $\mathbf{R}$ \\
\hline Nitrofurazona & $100 \mathrm{mcg}$ & + & + & + & ++ & + & ++ & ++ & + \\
\hline Nitrofurantoina & $100 \mathrm{mcg}$ & +++ & ++ & ++ & +++ & ++ & ++ & ++ & ++ \\
\hline Furazolidona & $100 \mathrm{mcg}$ & +++ & +++ & ++ & +++ & ++ & +++ & ++ & ++ \\
\hline
\end{tabular}

\footnotetext{
$R$ - resistente (ausencia de halo)

+ - pouco sensivel (até $10 \mathrm{~mm}$ )

++- sensivel (de 11 a $15 \mathrm{~mm}$ )

+++ - muito sensivel (acima de $15 \mathrm{~mm}$ )

(*) cloridrato de tetraciclina

(*) fenoximetilpenicilina hidroxist. dlet. dlam. metil. tetraciclina,
}

\section{D I S C U S $\AA$ O}

Não é fácil comparar os resultados obtidos por nós com os de BRYANS et al. ${ }^{3}$, e de GARBERS \& MONTEVERDE ${ }^{5}$, porquanto, esses autores não citam, em seus trabalhos, a concentraçāo dos antibióticos nos discos empregados, os critérios de exe- cução e o número de amostras utilizadas nas provas.

Sabe-se que enquanto alguns advogam discos de concentração única, outros indicam o uso de discos com diferentes concentraçōes (altas e baixas) de cada antibiótico, achando que assim, melhor se expressariam os resultados. 
CURY, R. - Senslbilidade da Salmonella abortivoequina a quimioterápicos e antib:bticos. Rev. Fac. Med. vet. Zootec. Univ. S. Paulo, 11:111-14, 1974.

Todavia, ressalvando-se esses aspectos e no sentido da utilização prática, verifica-se que os citados como melhores por BRYANS et al. ${ }^{3}$, não coincidem com os de nossas verificaçôes, excetuando a nitrofurantoina, para a qual algumas de nossas amostras foram muito sensiveis embora a maioria tenha sido regularmente sensivel.

Dentre os indicados por GARBERS \& MONTEVERDE, coincidem com os nos- sos resultados, o cloranfenicol e, em parte, a nitrofurantoina e a furazolidona.

\section{CON C L U S O}

Antibiogramas realizados mostraram que a Salmonella abortivoequina foi muito sensível ao cloranfenicol, kanamicina, metaciclina, cefaloridina, cefalotina e penetracina.

RFMV-A/12

CURY, R. - Salmonella abortivoequina sensivity to chemotherapeutic and antibiotic substances. Rev. Far. Med. vet. Zootec. Univ. S. Paulo, 11 : $11: 111-14,1974$

SUMMARY: Eight strains of Salmonella abortivoequina, of various origins, were tested with nineteen different antibiotics, one antifungal and three chemiotherapic Conclusions of these antibiograms where that Salmonella abortivoequina are very sensitive to: chloramphenicol, kanamycin, methacycline, cephaloridine, cephalothin and penetracine.

UNITERMS: Salmonella abortivoequina *; Sensivity*; Chemotherapeutic *; Antibiotic*.

\section{REFERENCIAS BIBLIOGRAFICAS}

1. Amato Neto, V. et al. - Antibióticos na prática médica. São Paulo, Ed. Gremed, 1972 .

2. BIERINGER, G. S. \& MIALE, M. D. Evaluation of a rapid dyereduction test for bacterial susceptibility to antiblotics. Amer. J. clin. Path., 36: 195-202, 1961

3. BRYANS, J, T. et al. - Equine salmonelosis. Cornell Vet., $51(4): 467-477$, 1961.

4. CROSSLEY, V. M. et al. - The use of solublestarch medium in the preparation of smooth "0" Salmonella antigens. J. Bact., s2(3):367-371, 1946.

5. GAREERS, G. V. \& MONTEVERDE, J. J. - Infecciones a enterobarterias en equinos. II. Poliartritis debidas a
Salmonella abortus equi. en ausencla de aborto contagloso. Rev. Med. vet. (B. Alres), 45(5):305-312, 1964.

6. LACAZ, C. S. et al. - Antibioticos. 2 ed. São Paulo, Ed. da USP, 1969.

7. WORLD HEALTH ORGANIZACION Standardization of methods for conIuting microbic sensivity test. Washington, 1961. (Report Series, n. 210)

8. WILleMS, R. \& STIERNET, A. - Le paratyphus du cheval. Une forme peu connue due a Salmonella abortus equi. Ann. Med. Vet., 89:106-110, 1945.

Recebido para publicacão em 28-8-74 Aprovado para publicação em 29-8-74 